\title{
Designing the Financial Tools to Promote Universal Access to AIDS Care*
}

\author{
Patrick Leoni \\ National University of Ireland at Maynooth \\ and \\ Stéphane Luchini \\ GREQAM-CNRS
}

*We would particularly like to thank F. Aprahamian, K. Arrow, P. Barrieu, F. Bloch, A. Casella, S. Cleary, A. Dixit, P.-Y. Geoffard, A. Kirman, M. Kremer, J.-P. Moatti and M. Teschl for many stimulating conversations and suggestions. This extends to the seminar participants at the PET 2005 conference and the Global Finance Conference 2005, as well as many other universities. We also benefited from collaborations within the Resource Needs Technical Working Group of UNAIDS. All remaining errors are ours. 


\begin{abstract}
We argue that reluctance to invest in drug treatments to fight the AIDS epidemics in developing countries is largely motivated by severe losses occurring from the future albeit uncertain appearance of a curative vaccine. We design a set of securities generating full insurance coverage against such losses, while achieving full risk-sharing with vaccine development agencies. In a general equilibrium framework, we show that those securities are demanded to improve social welfare in developing countries, to increase current investment in treatments and the provision of public goods. Even though designed for AIDS, those securities can also be applied to other epidemics such as Malaria and Tuberculosis.
\end{abstract}

Keywords: HIV/Aids funding, security design, therapeutic innovation, health underinvestment, HIV/Aids vaccine.

JEL codes: I1, I3, G15 


\section{Introduction}

The scale of the HIV/AIDS epidemics has exceeded the most pessimistic forecasts: some 42 million people worldwide are currently estimated to be HIV-infected and $95 \%$ of these live in developing countries. Five to six million of those living with HIV/AIDS are probably in need of antiretroviral (ARV) drugs (UNAIDS 2003).

To tackle this crisis, the international community has increased funding in order to subsidize access to ARV drugs (Moatti et al. 2003) in developing countries, since this life-long ARV drugs treatment has proven to be highly efficient in drastically reducing morbidity and mortality associated with HIV infection. Specifically, those funds aim to foster prevention, staff training, building capacities and local drugs production in developing countries. One of the motivations of this campaign is that, beyond the medical emergency, fighting AIDS is also a critical part of reducing the poverty gap worldwide as argued by Sachs (2004).

A total of US $\$ 8.3$ billion have been estimated to be available in 2005 from a range of different financial sources including the G7, the European Commission and the Global Fund, and about US\$ 8.9 billion and US\$ 10 billion in 2006 and 2007 respectively. Additionally, an estimated US $\$ 2.6$ billion for 2005 , US $\$ 2.8$ billion for 2006 and US $\$ 3$ billion for 2007 are to be provided by domestic spending (public and out-of-pocket expenditures by affected individuals and families) in the 135 middle and low-income countries. This amount is not expected to significantly increase. 
Nevertheless, governments' investments in developing countries do not match the magnitude of the problem, since " $\ldots$ some countries are in a position to contribute more government resources to [fight] AIDS" (UNAIDS (2005), p. 11). For instance, the estimated number of people receiving ARV therapy in developing countries currently ranges between 630000 and 780000 , which corresponds to a $12 \%$ coverage rate of estimated patients in need of treatment (WHO 2004). Current investments in ARV therapy are nonetheless critical to control the propagation of the epidemics and its economic externalities, on top of reducing current mortality (Moatti et al. 2004).

The main explanation advanced so far to this reluctance to invest is that ARV costs are prohibitive and represent a major crowding out of public resources (Harling et al. 2005). For instance, AIDS-related expenditures amounted to already $0.842 \%$ of the total expenditures of South Africa in 2004 (Blecher and Thomas 2005).

Our contribution regarding this reluctance to invest in drugs treatments is twofold. We first argue that the future albeit uncertain appearance of a therapeutic vaccine, more effective both medically and economically, is a major disincentive to current investment. The intuition is that this innovative treatment technology will trigger severe losses in terms of sunk costs and upgrading costs when introduced, as detailed later. Reluctance to invest is thus a rational economic consequence with a direct impact on the death toll and the evolution of the epidemics (Dixit and Pindyck (1994), Chapters 5-9). Second, we design a set of financial securities generating full insurance coverage against such losses for developing countries, while achieving full 
risk-sharing with bodies in charge of developing the vaccine. We show that those securities are demanded to increase social welfare in developing countries, current investments in treatments and R\&D funds in innovative treatment technologies.

In the specific case of AIDS, the most promising and innovative technology is a therapeutic vaccine, capable of both treating infected patients and reducing HIVtransmissibility by diminishing the mean viral load in the population. The vaccine could therefore delay the need for ARV drugs for several years (see Wei et al. (2004) and ANRS (2004) for the latest developments in HIV vaccine research). Such effects can be achieved with one injection only, and the production cost is small.

Developed countries, mostly the U.S. and France with public funds up to $90 \%$ (Kremer and Glennerster 2004), are developing such a therapeutic vaccine to be delivered at no cost (or at production cost) to developing countries. Current estimates of worldwide spending in HIV vaccine research range between US\$ 600-650 million, as detailed in Kremer and Glennester (2004) and IAVI (2004).

The remainder of the paper is organized as follows. In Section 2, we describe the losses generated by the vaccine appearance, in Section 3 we design the securities allowing full insurance coverage against such losses and achieving full risk-sharing with vaccine development agencies, in Section 4 we carry out a welfare analysis showing that our securities are demanded to increase social welfare and current investments in drugs therapy, in Section 5 we detail the policy implications for AIDS financing campaigns and other epidemics, and the Appendix contains all the technical proofs. 


\section{Economic impact of the vaccine}

We now study the economic consequences of a vaccine appearance. The problematic aspect of ART provision, and more generally of health investments, is that switching from technology to another is particularly costly (Palmer and Smith 2000). This is true for investments in developing countries, and also for bodies currently producing the drugs. Nevertheless, actual costs in the case of AIDS are typically difficult to accurately estimate, mostly because of lack of reliable data and field studies. We rely on available aggregate data from international agencies such as the United Nations to document this problem.

The most natural consequence of a vaccine appearance is that sunk costs in ARV investments will be lost. Often forgotten albeit important sunk costs are managerial costs (also called program level costs) arising at administrative levels outside the point of health care delivery. Such costs include services such as management of AIDS Programs, monitoring and evaluation, staff training, supervision of personnel and patient tracking. Managerial costs are particularly stringent because most decisions remain at government level, instead of a centralized body coordinating actions (Gupta et al. 2004). United Nations estimations assert that such costs amount to US\$1.236 billion in 2006, US\$ 1.095 billion in 2007 and US\$ 1.281 billion for all 135 low and middle income countries (UNAIDS 2005). In South Africa for instance, program level costs are estimated to be $8 \%$ of the global investment in ARV treatment program over the same period (Cleary et al. 2005). 
Other managerial aspects might also trigger sunk costs when a vaccine becomes available. For instance, short-run inefficiencies are likely to occur when resources such as HIV-dedicated hospitals and services are re-oriented to other activities. This reorientation will critically depend on managerial supervision, and the magnitude of the inefficiency may turn out to be severe in countries where the public sector has very limited managerial capacity (Dixit 2003).

Other severe losses are on the drugs production side. Even if drug plants can partially be redirected to the production of other drugs such as antibiotics, the nature of ARV treatment will make any reshuffling of the whole production process particularly costly. Indeed, the pharmaceutical industry traditionally suffers from rigid manufacturing with strongly specialized production equipment, together with costly regulatory requirements (Shah 2004). In case of reshuffling of a production chain, regulatory requirements will impose for instance that all expensive quality control tests will have to be renewed (Blau et al. 2000). Another costly aspect of drugs manufacturing is the extensive use and processing of intermediary goods (primary active ingredients), with lengthy periods to obtain some of those goods and specific processing technologies. Switching from one production to another will necessarily require to change most stages of the production chains, with new equipment needed at every level (Shah 2004). An accurate evaluation of those reshuffling costs requires case-by-case field studies to estimate them; however, there is a growing literature in Engineering emphasizing that such costs should be significant (Shah 2005). 
Another consequence of a vaccine appearance is that resources from international agencies, subsidizing governments to foster treatments (up to $76 \%$ of the overall budget worldwide in 2005; UNAIDS (2005)) will no longer be available to developing countries. A significant amount of international subsidies will be reallocated to the vaccine production, more effective both economically and medically, leading in turn to a decrease in subsidies to developing countries. This issue is critical since health infrastructures in developing countries, built and operated mostly with international subsidies, will then have to be operated with national funds. Whether it remains costeffective to operate all HIV-dedicated hospitals and services and to reshuffle all drugs factories cannot be established from aggregate data, although when doing so one must consider the crowding-out effect of such costs in situations of limited resources and no international subsidies.

Investments in health infrastructures are made to fight a major national crisis such as AIDS. With this crisis about to end, as it would conceptually be the case with a therapeutic vaccine, reallocation of all such investments to other health issues will likely lead to significant overspending in less critical national priorities. Independently of the positive externalities in health services, developing countries also need resources to face many other critical challenges such as water supply and famine.

When anticipated, the above losses explain current under-investment in comparison to a situation where opportunities to hedge against the risk of a vaccine appearance exist. The next section is devoted to designing such insurance opportunities. 


\section{Designing the securities}

The question that we now address is what financial tools can be designed to foster current investments in ARV treatments, allowing to hedge against the future albeit uncertain availability of this innovative treatment technology.

A standard insurance contract, allowing a particular government to cover production losses associated with a successful vaccine, is ineffective in practice. Indeed, the main shortcoming of such a contract is that it would transfer the risk to the issuer, who would be unable to diversify a large part of the transaction. Given current regulatory practices, the value at risk associated with such a contract would typically be too high to be allowed.

We next describe a set of financial securities tackling all of the above problems. Those securities take the form of derivatives with payment contingent on the appearance (or not) of a successful vaccine to be issued both by insurance companies and international agencies, with the idea of "securityzing" a broad insurance contract. Our construction is reminiscent of Shiller's proposition to create macro securities (Shiller 2003). While Shiller designs his construction as a way of hedging risks at an individual level, we consider a mechanism that is at an institutional level. A financial tool allowing governments to hedge against vaccine appearance can be constructed as follows. Consider a financial asset available at the time decisions to produce ARV are made, with a fixed maturity date and small payoff if a successful vaccine is released before the maturity date. Somewhat similar types of derivatives are weather deriva- 
tives, with the common idea that the security has no underlying real asset. We call this derivative an Arrow security. The welfare analysis developed in the next section shows that Arrow securities are demanded by developing countries to increase social welfare as well as current investments in ARV treatment. Such securities will also naturally be demanded by pharmaceutical companies producing drugs. There are two reasons for this demand. First, ARV drugs are still patented in developed countries, whereas following the Doha Declaration in 2003 WTO regulations offer possibilities for developing countries affected by AIDS to overcome existing intellectual property rights through compulsory licensing. Second, marketing a therapeutic vaccine would render de facto current drugs patents virtually obsolete.

Since full risk-transfer is impossible with the above security alone, profit-seeking organizations are naturally unwilling to market such securities. This problem can be solved by introducing the complementary asset of the Arrow security. Consider a financial asset identical to an Arrow security, with the difference that the same payment is made if a vaccine is not approved for distribution by an independent testing agency before maturity date; further conditions on payment delivery must be added to remove a natural moral hazard, as detailed later. This complementary asset is demanded by public agencies responsible for developing the vaccine, since failure can henceforth be financially compensated leading to additional funds for further research. This security can also induce typically reluctant private companies to engage in vaccine R\&D (Kremer and Snyder 2004; Geoffard and Philipson 1997). 
A natural moral hazard is that vaccine companies, even public, purchase this complementary security without making necessary investment to obtain a vaccine. There are two main aspects to this moral hazard. The first aspect is that a vaccine company may start the testing trial with a product where small (if any) $R \& D$ investment has been made. The second aspect is that such a company may not pay for further testing and thus generate profits by exercising the complementary security. This last aspect is important since, in practice, the trial is paid for by the pharmaceutical company for a total that amounts to one-third of the development budget (Klausner et al. (2003)). Those issues can be removed by making payment contingent on some standard decisions by health control agencies (such as for instance the F.D.A. in the U.S.) to approve distribution, as follows.

The first aspect above can be removed by making payment conditional on approval by the testing agency to start the trial for at least one vaccine, based on enough scientific evidence that the candidate vaccine can be successful. ELISPOT assays, as described in IAVI (2004), are reliable pre-tests for this purpose. Failure to get this approval prevents payment, and thus significant investment in R\&D to obtain a testable product becomes necessary to exercise the complementary security.

The second aspect can be solved by requiring that payment be also conditional on the approval from the testing agency to stop all the trials before their end, instead of unilateral withdrawals from vaccine agencies. With this last condition, vaccine agencies cannot avoid testing costs if they want to exercise the security. 
Another critical aspect for implementation is the estimation of the risk; i.e., in our case the estimation of the probability of appearance of a successful vaccine. The scientific and technical procedure to fulfill in order to certify the effectiveness of a new product are well defined with a high level of quality control, and allows for such an estimation. For instance, mandatory progress reports during the testing trial, as described in Klausner et al. (2003) for AIDS vaccines and routinely done for all other tested drugs, allows to compute the conditional success probability of the vaccine over time, when compared to the performances of similar products during their trials.

The combination of the Arrow security and its complementary naturally allows for complete risk-transfer, and thus these securities are issuable in the same way as all other existing securities. Insurance companies can simply cancel out the risk by issuing an equal number of both securities, and generate profits through their intermediary function. Given relative investments in vaccine development and drug production, the demand for the Arrow security should be greater than that for its complement. International agencies in charge of promoting access to drug treatment can then take the residual risk by issuing Arrow securities, and possibly charging a premium in the form of a reduction in subsidies to developing countries. Our welfare analysis also directly implies that security issuance is more efficient than direct subsidies. As a whole, our construction implies that every party can fully cover the risk of the appearance (or not) of a vaccine (see Figure 1). 


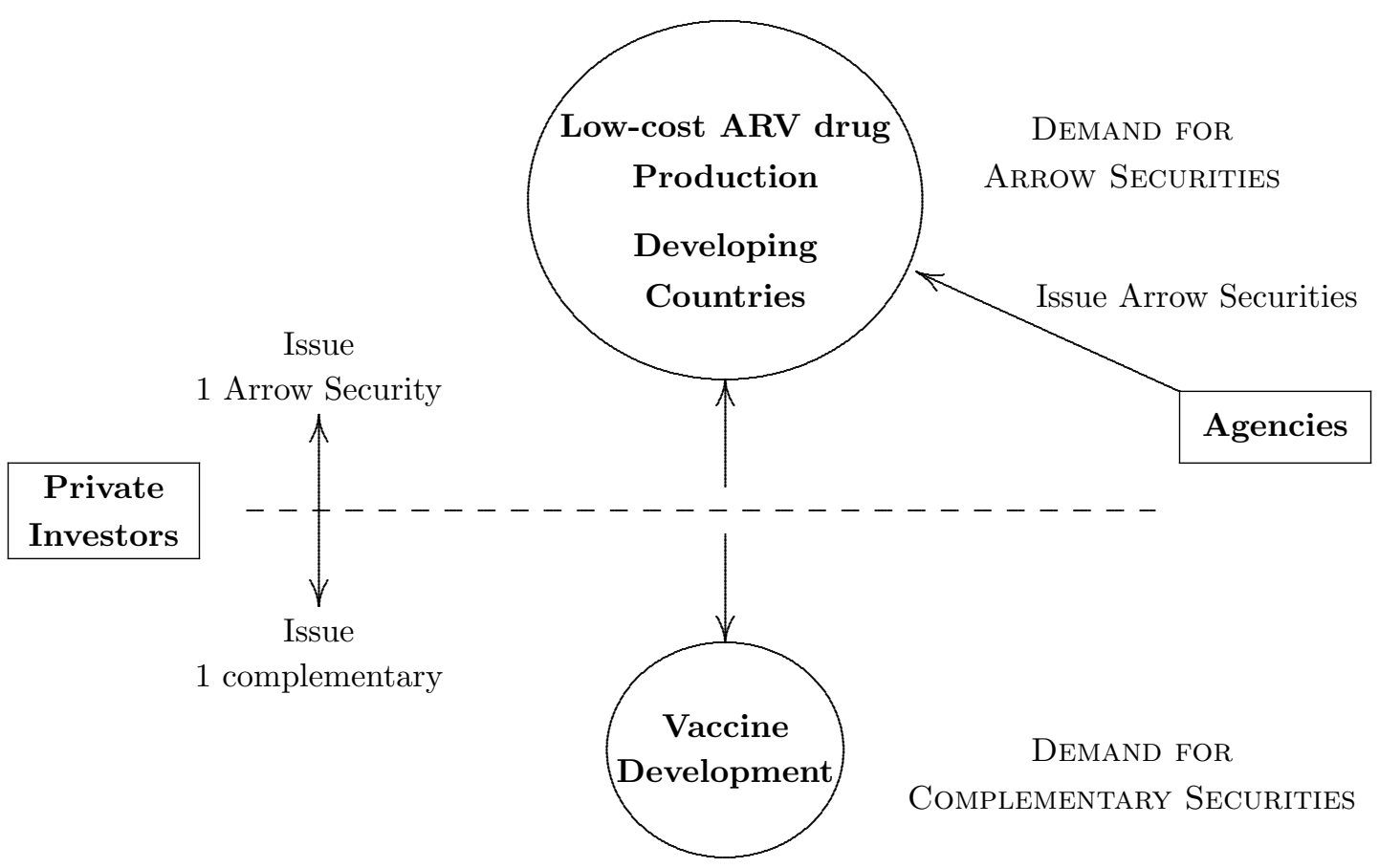

Figure 1: Issuance and demand for securities

In the next section, we develop a two-period model representing a typical HIV/AIDS care decision setting for a developing country, in a general equilibrium framework encompassing all the above issues. This analysis aims to show that the demand for Arrow securities is motivated by welfare considerations.

In our framework, the government allocates resources to enhance national consumption, provision of a public good and production of ARV treatments for a given level of endowments (which include a given level of international subsidies). There is also a vaccine agency in charge of developing the vaccine as well as distributing it to the government at no cost. This agency allocates its own endowment between funding the vaccine distribution to the government if the vaccine $R \& D$ campaign is successful, and refinancing a new R\&D campaign otherwise. We assume that in the second period a vaccine is available with exogenous positive probability; that is, 
we assume that current investment from the vaccine agency does not influence the success probability.

Arrow securities and their complementaries are issued by a large number of riskaverse investors having access to a complete financial market. Investors have standard von Neumann-Morgenstern preferences, and we assume that there is zero-covariance in return between the Arrow security and a large market portfolio. A straightforward application of the beta-pricing formula to this setting implies that the equilibrium price of one Arrow security paying off one unit of consumption good equals the probability of appearance of the vaccine (actuarial price). We then show that, if the level of international subsidies decreases as a consequence of the availability of the vaccine, the optimal reaction of a government is to increase its security holdings. We also show that the introduction of Arrow securities strictly improves expected social welfare. Finally, holding of Arrow securities is shown to guarantee a higher level of treatment investments and a higher level of provision of the public good.

The intuition behind our results is that, when faced with the risk of a drop in contingent endowment, the need to smooth out losses from ARV production becomes more and more pressing for a developing country. The Arrow security is the only way to achieve this optimal smoothing. At a more abstract level, the reason for this improvement is that our securities allow to switch from an uninsurable risk to complete financial markets where every insurance needs are met. 


\section{The model}

We next develop a formal model that encompasses the previously described issues in a General Equilibrium framework. We will put the emphasis on showing that Arrow securities are demanded by governments in developing countries to foster social welfare, provision of public goods and investments in drug treatments. All the technical proofs in this section are given in the Appendix.

There are two periods $(t=0$ and $t=1)$, and a given population of infected patients in period 0. A benevolent government is in charge of treating the patients. Every infected agent must receive medical treatment in period 1, or else dies during this period. Potentially, there are two forms of medical treatment that guarantee the survival of the infected patient. The first one is a pill of ARV drug, with the assumption that technical knowledge exists in period 0 to start production in period $1 .^{1}$ The alternative to this treatment is a therapeutic vaccine (or any other innovation outdating existing treatments) available in period 1 with positive probability described next.

\subsection{The vaccine agency}

The vaccine is developed in period 0 by a vaccine agency. In period 1 , it becomes common knowledge whether the development campaign started in period 0 is success-

\footnotetext{
${ }^{1}$ For instance, this pill can be a Fixed Dose Combination (FDC) currently produced by Indian firms. Luchini et al. (2003) analyzes the current provision of ARV drugs in developing countries.
} 
ful. If the vaccine is available in period 1 , the agency funds a distribution campaign to treat the infected population. Otherwise, the agency seeks to finance a new $R \& D$ campaign to start in period 1 . To simplify the analysis, we assume that period 0 investments in $R \& D$ are already in place, and thus financial decisions do not affect the success probability of the vaccine development. Thus, we assume that a vaccine appears in period 1 with exogenous probability $\alpha>0$. The agency has an initial exogenous endowment $w_{0}^{a}>0$ of consumption good in period 0 , which can be allocated to hedge against period 1 events. The agency also receives an endowment $w_{1}^{a}>0$ of consumption good in period 1 if the development campaign is successful to fund the distribution to developed countries, and $w_{2}^{a}>0$ to fund another R\& D campaign in case of failure. We assume that $w_{2}^{a}>0$ is significantly smaller than $w_{1}^{a}>0$ so that the agency must hedge against failure to successfully develop the vaccine. Let $\rho>0$ (resp. $\sigma>0$ ) denote the funds allocated in period 0 to the distribution campaign (resp. to the new $\mathrm{R} \& \mathrm{D}$ campaign). From a bundle $(\rho, \sigma)$, the vaccine agency receives the utility

$$
U_{a}(\rho, \sigma)=\alpha \Pi_{1}(\rho)+(1-\alpha) \Pi_{2}(\sigma),
$$

where $\Pi_{i}(i=1,2)$ is a strictly increasing, strictly concave function and continuously differentiable function. The functions $\Pi_{i}$ ' can be regarded as continuation functions describing the objectives above; moreover, the budget constraints faced by the agency to funds those campaigns will be described later after describing the financial tools allowing to hedge against variations in subsidies as described above. 


\subsection{The government}

We now describe the government decision problem. The government can turns the consumption good into ARV treatments and a public good, or can also consume directly. The government thus faces a problem of optimal allocation of resources between national consumption, treatment of the infected population and the provision of a public good such as schools or roads.

The government receives an exogenous endowment $w_{0}>0$ of consumption good in period 0. This endowment is the only source of revenue, which can come from capital in place, direct taxation and/or international subsidies. In period 1, the government has an endowment of consumption good $w_{1}>0$ if the vaccine is available, and $w_{2}>0$ otherwise. We assume that $w_{1}$ is significantly smaller than $w_{2}$ for the reasons described in Section 2, giving incentives to the government to hedge against this fluctuation in endowments in a way described later with the government budget constraints. Let $c_{0}$ denote the amount of consumption good consumed in period 0 , and let $c_{1}$ (resp. $c_{2}$ ) denote the amount of consumption good consumed in period 1 if the vaccine is available (resp. if not available).

The government is also in charge of producing a public good and ARV treatments. Those are produced in period 0 , and are distributed at no cost to the population in period 1. For sake of simplicity, we assume that for any amount of consumption good $g \geq 0$, the government uses a one-to-one technology to produce a measure $g$ of public good. 
The government also uses a one-to-one technology to produce ARV treatments. A measure $T$ of ARV treatment has two components, one component $g^{\prime}$ that can be turned into public good if the vaccine appears, and a component $d$ that is AIDS specific and is lost if a vaccine appears. The component $d$ will be called treatments. To simplify the analysis, we assume that the component $g^{\prime}$ is embedded into the provision of public good $g$.

The public good and treatments produced are distributed to the population at no cost (public good and treatments are not marketable). If the vaccine is available, it is distributed to the population at no cost to the government by the agency. The utility derived by the government from a sequence $\left(c_{0}, c_{1}, c_{2}, d, g\right)$ is given by the welfare function

$$
U\left(c_{0}, c_{1}, c_{2}, d, g\right)=u\left(c_{0}\right)+\beta \alpha\left[u\left(c_{1}\right)+v(g)\right]+\beta(1-\alpha)\left[u\left(c_{2}\right)+v(g)+\Gamma(d)\right],
$$

where $\beta>0$ is an intertemporal discount factor, and where the functions $u, v$ and $\Gamma$ are all strictly increasing, strictly concave, twice-continuously differentiable and satisfy the Inada conditions. The function $\Gamma$ measures the specific emphasis on treating the infected population regardless of possible losses. The function $u$ (resp. $v$ ) measures the utility derived from consumption good (resp. public good). The functions $\Gamma$ and $v$ can depend on the level of infected population, political priorities or other demand for health expenditures.

The separability of the objective function in (2) captures the idea that there is no substitution effect across goods and across time, and it is not central to our analysis. 
Similar qualitative results obtain by assuming, instead of separability, supermodularity of the objective function or a single crossing property on some parameters of the economy (see Topkins (1998) for a mathematical introduction). The mathematical difficulties raised by those weaker assumptions are beyond the scope of our analysis.

\subsection{The financial tools}

We also assume that the government and the agency trade securities to hedge against the appearance (or not) of the vaccine. The need to the government for this hedging opportunity arises from the loss of prior investment in treatments in the event of a successful vaccine. In the same manner, the need to the vaccine agency is motivated by losses incurred in restructuring the R\&D in case of non-appearance.

We next describe the financial tools making those insurance opportunities possible. Consider a financial asset available in period 0, paying off one unit of consumption good next period if the vaccine is made available and 0 unit of consumption good otherwise. We call this asset an Arrow security. This Arrow security works as an security with maturity date being one period ahead and payment contingent on the introduction of the vaccine. If the vaccine is not available in period 1, the Arrow securities become worthless. Define the complementary security as above, with the

only difference that it pays off 1 unit of consumption if the vaccine does not appear and 0 otherwise. 


\subsection{International investors}

Arrow securities and the complementary securities are traded (or issued) by international investors represented by an arbitrary non-empty set $I$, which have access to a large financial market assumed to be complete. In more details, any investor in this outside market faces $L \geq 2$ intrinsic events independent of the vaccine appearance, each event $l(l=1, \ldots, L)$ receives probability $\gamma_{l}>0$ all summing up to 1 . We incorporate the new risk of a vaccine appearance as follows: every intrinsic event $l$ is separated into two events $l_{1}$ and $l_{2}$, where $l_{1}$ corresponds to event $l$ with vaccine appearance (thus occurring with probability $\gamma_{l} \cdot \alpha$ ) and $l_{2}$ is the event $l$ without vaccine appearance occurring with probability $\gamma_{l} \cdot(1-\alpha)$.

When describing above the objective of the agency and the government, we have implicitly assumed that those bodies consider the intrinsic events in this outside market to be undistinguishable, and thus they do not seek to hedge against them. The same results hold by removing this last assumption, we maintain it to simplify the exposition. Investors trade $J \geq L$ securities, and every security $j$ purchased in period 0 yields in period 1 a dividend $d_{j}^{l} \geq 0$ in consumption good if the intrinsic event $l$ occurs. Investors also trade Arrow securities and complementary securities. We assume that this outside financial market is complete, and thus contains a risk-free asset whose return is normalized to 1 .

Every investor $i$ receives an endowment in consumption good $w_{0}^{i}>0$ in period 0 , and contingent endowment $w_{l_{j}}^{i}>0$ if the event $l_{j}(l=1, \ldots, L$ and $j=1,2)$ occurs in 
period 1 .

Investors are risk-averse and take financial positions so as to maximize the standard utility function

$$
V\left(c_{0}, \tilde{c}\right)=f\left(c_{0}\right)+E[f(c)]
$$

where $\tilde{c}$ is the vector of consumption good in period $1, E[$.$] is the expectation operator$ associated with the economic uncertainty in the outside market, and $f$ is a strictly increasing, strictly concave and continuously differentiable function. The budget constraints faced by the international investors is described in the next section.

\subsection{Budget constraints and equilibrium definition}

We now describe the problem faced by the government, the vaccine agency and the international investors. Let $z_{a}$ denote the amount of Arrow securities purchased by the government, and let $p_{a}$ be the price of one security. The budget constraint in period 0 faced by the government is given by

$$
c_{0}+g+d+p_{a} z_{a} \leq w_{0}, \text { and } c_{0}, g, d \geq 0
$$

In the above, we have not restricted security holdings to being positive, thus allowing for short sales. We will later give a sufficient condition, based on contingent endowments, ensuring that the government holds a strictly positive quantity of securities. It is also easy to see that short-selling also allows not to consider holdings of the complementary security in (4). 
In period 1 , contingent on the availability of the vaccine and with a holding $z_{a}$ of Arrow securities, the budget constraints are given by

$$
c_{1} \leq w_{1}+z_{a}, c_{1} \geq 0 \text { and } c_{2} \leq w_{2}, c_{2} \geq 0 .
$$

We next describe the budget constraint of the vaccine agency. Let $z_{c}$ denote the amount of complementary securities purchased by the government, and let $p_{c}$ be the price of one security. The budget constraint in period 0 of the vaccine agency is given by

$$
\rho+\sigma+p_{c} z_{c} \leq w_{0}^{a}
$$

and in period 1 the budget constraints are given by

$$
\rho \leq w_{1}^{a}, \rho \geq 0 \text { and } \sigma \leq w_{2}^{a}+z_{c}, \sigma \geq 0 .
$$

Here again, the possibility of short-selling the complementary security allows not to consider holdings of Arrow security in (6). Moreover, the drop in contingent endowments as described in Section 4.1 justifies the holdings of complementary securities only.

Finally, we define the budget constraints of the international investors. Let $p_{j}$ be the period 0 purchasing price of security $j$ on the outside market and let $\theta_{j}$ be the holding of this security $j$. The budget constraint in period 0 of investor $i \in I$ is

$$
c_{0}+p_{c} \theta_{c}+p_{a} \theta_{a}+\sum_{j} p_{j} \theta_{j} \leq w_{0}^{i},
$$

and in period 1 they are given for every intrinsic event $l$ by

$$
c_{l_{1}} \leq w_{l_{1}}^{i}+\theta_{c}+\sum_{j} d_{j}^{l_{1}} \theta_{j} \text {, and } c_{l_{2}} \leq w_{l_{2}}^{i}+\theta_{a}+\sum_{j} d_{j}^{l_{2}} \theta_{j} .
$$


Let $\theta^{i}$ be the vector of holdings of securities for investor $i$, and let $c^{i}=\left(c_{0}^{i}, c_{1_{1}}, \ldots, c_{L_{2}}\right)$ be her vector of contingent consumption. Let also $p_{M}=\left(p_{j}\right)_{j=1, \ldots, J}$ denote the vector of asset prices on the outside market.

We can now define an equilibrium for this economy.

Definition 1 A financial equilibrium is a sequence $\left(\bar{c}_{0}, \bar{c}_{1}, \bar{c}_{2}, \bar{d}, \bar{g}, \bar{z}_{a}, \bar{\rho}, \bar{\sigma}, \bar{z}_{c}\right)$, a sequence $\left(\bar{c}^{i}, \bar{\theta}^{i}\right)_{i \in I}$ and asset prices $\left(\bar{p}_{a}, \bar{p}_{c}, \bar{p}_{M}\right)$ such that

1. taking as given $\bar{p}_{a}$, the sequence $\left(\bar{c}_{0}, \bar{c}_{1}, \bar{c}_{2}, \bar{d}, \bar{g}, \bar{z}_{a}\right)$ is a solution to the program of maximizing (2) subject to (4) and (5);

2. taking as given $\bar{p}_{c}$, the sequence $\left(\bar{\rho}, \bar{\sigma}, \bar{z}_{c}\right)$ maximizes (1) subject to (6) and ( 7$)$;

3. taking as given $\left(\bar{p}_{a}, \bar{p}_{c}, \bar{p}_{M}\right)$, for every $i$ the sequence $\left(\bar{c}^{i}, \bar{\theta}^{i}\right)$ maximizes (3) subject to (8) and (9);

4. all markets clear.

Thus at the equilibrium, the government seeks to maximize its utility function taking the asset price of the Arrow security as given, so does the vaccine agency with the price of the complementary security, and risk-averse investors maximize their objective functions taking as given all the asset prices. As usual in general equilibrium models, the asset price is determined by market clearing conditions. One can also notice that the equilibrium price of the Arrow security must be strictly positive, since otherwise by (4) and (5), and together with the fact that the functions $u$ and $v$ are strictly increasing, the government would have an infinite demand for this asset. The 
same holds for the complementary security, since otherwise the vaccine agency would have an infinite demand by the same reasoning.

We next impose a condition on the correlation between the risk of a vaccine appearance and a market portfolio.

Assumption 2 There is a market portfolio $m$ lying on the mean-variance frontier, such that there is 0-covariance in return between $m$ and the Arrow security.

In practice, any standard market index can be considered to meet the requirement in Assumption 2. The above assumption is natural, since it seems unlikely that a nonpatented product has a significant impact on a large portfolio such as the S\&P 500 . This assumption allows to pin down the equilibrium price of the security, following standard arguments of the CAPM (see Leroy and Werner (2001), Chapter 17-19). Following again a CAPM type of argument, Assumption 2 also implies that Arrow securities can be used as any other tool to diversify any risk faced by international investors. The next result is a straightforward consequence of the beta-pricing formula, when applied to our setting.

Proposition 3 In equilibrium, we have that $\bar{p}_{a}=\alpha$.

Proposition 3 states that the equilibrium price of the Arrow security is exactly the probability of appearance of the vaccine. Such price corresponds to the actuarial price (or fair price) that any investor would expect in a real market for this asset. 


\subsection{Welfare analysis}

We now study some welfare properties of a financial equilibrium. We first carry out some comparative statics on the fundamentals of the economy. In particular, we are interested in analyzing the effect of a drop in international subsidies on the holding of Arrow securities if a vaccine becomes available. Such a decrease in international subsidies can be justified by a reallocation of resources at an international level to the production and distribution of the vaccine.

Proposition 4 In equilibrium, if $w_{1}$ decreases and all else remains equal, then the equilibrium holding of Arrow securities increases.

Proposition 4 states that a drop in international subsidies, as a consequence of the appearance of a vaccine, leads the government to increase its security holdings. The intuition is that, when facing the risk of a drop in contingent endowment, the need to smooth out loss of drug production becomes more and more stringent to the government. The Arrow security is the only way in our economy to achieve this optimal smoothing.

At this point, the government still has the opportunity to short-sell the security, depending on the level of contingent endowments. The possibility of short-sales shows an additional property of the Arrow security: the government can also use the asset to smooth out contingent consumption of various goods even if the vaccine does not appear. If contingent endowment in this last event is anticipated to be high, the government can thus short-sell the security to increase contingent consumption in 
the event of non-appearance. The optimal level of security holdings in Proposition 4, which includes the possibility of short-sales, depends on various fundamentals of the economy such as government preferences and contingent endowments.

Our next result gives a sufficient condition on contingent endowments ensuring no short-sale of Arrow securities in equilibrium.

Proposition 5 There exists $e>0$ such that, for every $w_{1} \leq e$, we have that $\bar{z}_{a}>0$ in equilibrium.

Propositions 4 and 5 together show that, if a significant drop in contingent endowment occurs in the event of a successful vaccine, the government finds it optimal to hold a positive amount of Arrow securities. Moreover, by Proposition 3, the equilibrium price of the Arrow security is not affected by a decrease in $w_{2}$. Thus, a moral hazard based on manipulation of international subsidies is ruled out in our setting. Hedging decisions are thus solely driven by consumption smoothing and welfare issues.

We next study the influence of the Arrow security on equilibrium supply of treatments and the public good. We first define a notion of equilibrium without financial assets. We call a sequence $\left(\tilde{c}_{0}, \tilde{c}_{1}, \tilde{c}_{2}, \tilde{d}, \tilde{g}\right)$ a production equilibrium if $\left(\tilde{c}_{0}, \tilde{c}_{1}, \tilde{c}_{2}, \tilde{d}, \tilde{g}\right)$ is solution to the program of maximizing (2) subject to (4)-(??) with the additional constraint that $z_{a}=0$. Thus, a production equilibrium is simply an optimal allocation of resources towards the production of various goods without access to financial tools. Our next result compares some properties of the financial and the production equilibria. 
Proposition 6 Assume that $w_{1} \leq e$, where e is given by Proposition 5. The equilibrium supply of the public good and treatments is strictly higher in a financial equilibrium than in a production equilibrium.

Proposition 6 compares equilibrium supplies of various goods, when contingent endowment is significantly low in the event of a successful vaccine. This case is the most relevant one, as explained in Section 2. Proposition 6 states that the introduction of the Arrow security increases drug production and public good delivery to the population. Thus, availability of the security allows the government to increase the number of treated patients without sacrificing efficiency. Since this increase would be impossible without the security, we have thus established the importance of our financial tool.

\section{Conclusion}

Our work shows that public investments in innovative treatments for current diseases is an economic disincentive to existing treatment production in developing countries. That is, developing countries are expected to rationally under-invest in existing treatment production when they cannot hedge against the introduction of innovative treatment technologies, the level of under-investment depending on anticipations of future medical innovations. This is not only the case for AIDS, as considered here, but also for major epidemics such as tuberculosis, malaria, sleeping sickness, Chagas disease and Dengue fever. The availability of financial securities allowing develop- 
ing governments to hedge against future innovations is shown here to foster existing treatment production, social welfare as well as innovative treatment technologies.

Thus, we argue that an international body's decision to invest in R\&D of not-yet patented treatments should be accompanied by the creation of financial securities such as the Arrow security and its complementary security introduced here. One of the limitations of our proposition is that international bodies themselves might be subject to moral hazard, since they could provide false information about future availability of technologies in order to manipulate governments' current investment decisions and the prices of the derivatives. Consequently, full transparency of information about R\&D is necessary to eliminate such a moral hazard and to allow for accurate estimation of the risk effectively taken by insurance companies.

The health sector is however well designed to guarantee such transparency. For instance, the Summit of Health Ministers held in Mexico in November 2004 endorsed a WHO proposal to establish an international platform to register all ongoing clinical trials sponsored either by the public or private sector. Biomedical journals are also issuing guidelines that would ultimately forbid publication of trial results that would not have been previously approved by this platform. 


\section{A Appendix}

We now prove the technical results stated earlier.

\section{A.1 Proof of Proposition 3}

Given our setting, we are typically in the situation of the CAPM. Moreover, since markets are complete, the equilibrium price must equal the marginal rate of substitution of any agent in the economy.

Consider now any international investor. The first-order conditions to her optimization program allows to pin down the unique pricing kernel of the economy as a function of her preferences. Following now exactly the same lines as Theorem 19.2.1 in Leroy and Werner (2001), by rearranging the terms of the pricing kernel and using the fact that the market return lies on the mean-variance frontier, we obtain that

$$
E\left(r_{a}\right)=\bar{r}+\beta_{a}\left(E\left(r_{m}\right)-\bar{r}\right),
$$

where $r_{a}$ (resp. $\left.r_{m}\right)$ is the return of the Arrow security (resp. market portfolio $m$ ), $\beta_{a}=\frac{\operatorname{cov}\left(r_{a}, r_{m}\right)}{\operatorname{var}\left(r_{m}\right)}$ is the usual "beta" for the Arrow security in the beta-pricing formula, and $\bar{r}$ is the risk-free return already normalized to be 1. By Assumption 2, we have that $\beta_{a}=0$ and (10) rewrites as

$$
E(a)=\bar{r}=1 .
$$

Since $E(a)=\frac{\alpha}{\overline{p_{a}}}$, we thus have that $\overline{p_{a}}=\alpha$ and the proof is complete. 


\section{A.2 Proof of Propositions 4}

The proof of Proposition 4 starts by analyzing the program faced by the government in equilibrium.

Since the utility functions are strictly increasing, the budget constraints in (4) and (5) must be binding. This implies that the program faced by the government can be rewritten as

$$
\operatorname{Max}_{d, g \geq 0, z_{a}} u\left(w_{0}-p_{a} z_{a}-d-g\right)+\beta \alpha u\left(w_{1}+z_{a}\right)+\beta(1-\alpha)\left(u\left(w_{2}\right)+\Gamma(d)\right)+\beta v(g) .
$$

We can now notice that, by the Inada conditions, the solution variables $(\bar{d}, \bar{g})$ to the above program must be strictly positive. Moreover, since we have placed no restriction on the security holding, the Lagrangian to the above programm is

$$
\mathcal{L}=u\left(w_{0}-p_{a} z_{a}-d-g\right)+\beta \alpha u\left(w_{1}+z_{a}\right)+\beta(1-\alpha)\left(\left(u\left(w_{2}\right)+\Gamma(d)\right)+\beta v(g) .\right.
$$

Taking the first order conditions, and using the price relation given in Proposition 3, we obtain the following equilibrium relations:

$$
\begin{aligned}
& u^{\prime}\left(w_{0}-p_{a} z_{a}-d-g\right)=\beta u^{\prime}\left(w_{1}+z_{a}\right), \\
& u^{\prime}\left(w_{0}-p_{a} z_{a}-d-g\right)=\beta v^{\prime}(g), \text { and } \\
& u^{\prime}\left(w_{0}-p_{a} z_{a}-d-g\right)=\beta(1-\alpha) \Gamma^{\prime}(g) .
\end{aligned}
$$


Rearranging the above equations, we obtain that

$$
\begin{aligned}
& u^{\prime}\left(w_{1}+z_{a}\right)=\beta v^{\prime}(g), \text { and } \\
& u^{\prime}\left(w_{1}+z_{a}\right)=\beta(1-\alpha) \Gamma^{\prime}(d), .
\end{aligned}
$$

To prove our result, we now proceed by way of contradiction. Assume that two endowments exist $w_{1}^{1}$ and $w_{1}^{2}$ such that $w_{1}^{1}>w_{1}^{2}$ and $\bar{z}_{a}^{1} \geq \bar{z}_{a}^{2}$. By (14), we must have that

$$
w_{0}-p_{a} \bar{z}_{a}^{1}-\bar{d}^{1}-\bar{g}^{1}>w_{0}-p_{a} \bar{z}_{a}^{2}-\bar{d}^{2}-\bar{g}^{2}
$$

Rearranging and using the fact that $\bar{z}_{a}^{1} \geq \bar{z}_{a}^{2}$, we get that

$$
\bar{d}^{2}+\bar{g}^{2}>\bar{d}^{1}+\bar{g}^{1}
$$

Moreover, by equations (17) and (18), we also have that $\bar{d}^{1}>\bar{d}^{2}$ and $\bar{g}^{1}>\bar{g}^{2}$. This contradicts equation (20), and the proof of Proposition 4 is now complete.

\section{A.3 Proof of Proposition 5}

To prove our result, we now proceed by way of contradiction. Assume that a sequence $\left(w_{1}^{n}\right)_{n \geq 0}$ and corresponding solutions $\left(\bar{z}_{a}^{n}\right)_{n \geq 0}$ exist, such that $w_{2}^{n} \rightarrow 0$ and $\bar{z}_{a}^{n} \leq 0$.

By Proposition 4, the sequence $\left(\bar{z}_{a}^{n}\right)_{n}$ is increasing and thus bounded from below. It follows that $\left(\bar{z}_{a}^{n}\right)_{n}$ converges to some $\tilde{z_{a}} \leq 0$. By equation (14), the expression $w_{0}^{n}-p_{a} \bar{z}_{a}^{n}-\bar{d}^{n}-\bar{g}^{n}$ converges to 0.

Moreover, it must be true that $\bar{g}^{n}$ and $\bar{d}^{n}$ converge to 0 for (17) and (18) to hold. 
Thus, it follows from the above that $p_{a} \bar{z}_{a}^{n}$ converges to $w_{0}$. Since $w_{0}$ is strictly positive, and since the price $p_{a}$ depends only on $\alpha$, we have established that $\tilde{z}_{a}>0$, which is a contradiction. The proof is now complete.

\section{A.4 Proof of Proposition 6}

In a financial equilibrium, it follows from (17) and (18) that the equilibrium quantities of public good and drugs must satisfy the following relations

$$
\begin{aligned}
& u^{\prime}\left(w_{1}+\bar{z}_{a}\right)=\beta v^{\prime}(\bar{g}) \text { and } \\
& u^{\prime}\left(w_{1}+\bar{z}_{a}\right)=(1-\alpha) \beta \Gamma^{\prime}(\bar{d}),
\end{aligned}
$$

where $\bar{z}_{a}$ is the optimal holding of Arrow securities. Since $w_{1} \leq e$, it follows from Proposition 4 that $\bar{z}_{a}>0$.

Without tradable securities, it must be true that $z_{a}=0$ is the solution to the program faced by the government, and thus we must have that

$$
\begin{aligned}
& u^{\prime}\left(w_{1}\right)=\beta v^{\prime}(\tilde{g}) \text { and } \\
& u^{\prime}\left(w_{1}\right)=\beta(1-\alpha) \Gamma^{\prime}(\tilde{d}),
\end{aligned}
$$

where $\tilde{g}$ and $\tilde{d}$ are optimal variables in the production equilibrium. Since $u^{\prime}, v^{\prime}$ and $\Gamma^{\prime}$ are monotonic functions, and since $\bar{z}_{a}>0$, it follows that $\bar{g}>\tilde{d}$ and $\bar{d}>\tilde{d}$. The proof is now complete. 


\section{References}

ANRS (2004). ANRS research on HIV vaccine. Scientific Information and Communication Office. Paris, France.

Blau, G., B. Mehta, S. Bose, J. Pekny, G. Sinclair, K. Keunker, and P. Bunch (2000). Risk management in the development of new products in highly regulated industries. Computers and Chemical Engineering, 24, 659-664.

Blecher, M. and S. Thomas (2005). Health care financing. In P. iJumba and A. Ntuli (Eds.), South African Health Review 2005. Durban: Health Systems Trust.

Cleary, S., O. Okorafor, W. Chitha, A. Boulle, and S. Jikwana (2005). Financing antiretroviral treatment and primary health care services. forthcoming in South African Health Review, Durban, Health Systems Trust.

Dixit, A. (2003). Some lessons from transaction-cost politics for less-developed countries. Economics and Politics, 15, 107-133.

Dixit, A. and R. Pindyck (1994). Investment under Uncertainty. Princeton University Press.

Geoffard, P-Y. and T. Philipson (1997). Disease eradication: Private vs. public vaccination. American Economic Review, 87, 222-230.

Gupta, R., A. Irwin, M.C. Raviglione, and J. Y. Kim (2004, January). Scaling-up treatment for hiv/aids: lessons learned from multidrug-resistant tuberculosis. The Lancet, 363, 320-324. 
Harling, G., R. Wood, and E. Beck (2005). Efficiency of interventions in HIV infection 1994-2003. Symposium of the IAEN Meetings in Cape Town.

IAVI (2004). Accelerating global efforts in AIDS vaccine research and development. International AIDS Vaccine Initiative, Technical report. Scientific Blue Print.

Klausner, R.D., A. S. Fauci, L. Corey, G.J. Nabel, H. Gayle, S. Berkley, B. F. Haynes, D. Baltimore, C. Collins, R. G. Douglas, S. Esparza, D. P. Francis, N. K. Ganguly, J. L. Gerberding, M. W. Makgoba, G. Pantaleo, P. Piot, Y. Shao, E. Tramont, H. Varmus, and J.N. Wasserheit (2003). The need for a global HIV vaccine enterprise. Science, 300, 2036-2039.

Kremer, M. and R. Glennerster (2004). Strong Medicine: Creating Incentives For Pharmaceutical Research On Neglected Diseases. Princeton University Press.

Kremer, M. and C. Snyder (2004). Why is there no AIDS vaccine? mimeo.

Leroy, S.R. and J. Werner (2001). Principles of Financial Economics. Cambridge University Press.

Luchini, S., B. Cisse, S. Duran, M. de Cenival, C. Comiti, and J.P. Moatti (2003). Decrease in prices of antiretroviral drugs for developing countries: from political "philantropy" to regulated markets? In J.P. Moatti, B. Coriat, Y. Souteyrand, T. Barnett, J. Dumoulin, and Y.A. Flori (Eds.), Economics of AIDS and access to HIV/Aids care in developing countries. Issues and challenges, Sciences Sociales et Sida, pp. 169-211. ANRS.

Moatti, J.P., I. N'Doye, S.M. Hammer, and M. Kazatchkine (2003). Antiretrovi- 
ral treatment for HIV infection in developping countries: an attainable new paradigm. Nature Medicine, 9, 1449-1452.

Moatti, J-P., B. Coriat, Y. Souteyrand, T . Barnett, J. Dumoulin, and Y.A. Flori (Eds.) (2004). Economics of AIDS and access to HIV/Aids care in developing countries. Issues and challenges. Sciences Sociales et Sida. Paris: ANRS.

Palmer, S. and P. Smith (2000). Incorporating option values into the economic evaluation of health care technologies. Journal of Health Economics, 19, 755-766.

Sachs, J.D. (2004). Health in the developing world: achieving the millennium development goals. Bulletin of the World Health Organization, 82, 947-9. discussion $950-2$.

Shah, N. (2004). Pharmaceutical supply chains: key issues and strategies for optimisation. Computers and Chemical Engineering, 28, 929-941.

Shah, N (2005). Process industry supply chains: Advances and challenges. Computers and Chemical Engineering, 29, 1225-1235.

Shiller, R.J. (2003). The new financial order. Risk in the 21st century. Princeton University Press.

Topkins, D.M. (1998). Supermodularity and Complementarity. Princeton University Press.

UNAIDS (2003). Progess report, the global response to HIV/Aids epidemic, 2003: follow-up to the 2001 united nations general assembly. Geneva, New York: UNAids, Technical report. Session on HIV/Aids. 
UNAIDS (2005, June). Resource needs for an expanded response to aids in low and middle income countries. Geneva: Joint United Nations Programme on HIV/Aids, Technical report.

Wei, L., L.C. Arraes, W.T. Ferreira, and J.M. Andrieu (2004). Therapeutic dendriticcell vaccine for chronic HIV-1 infection. Nature Medecine, 10, 1359 - 1365.

WHO (2004). "3 by 5" progress report. World Health Organization and Joint United United Programme on HIV/Aids, Technical report. NLM : WC 503.2. 